\title{
Effects of Prepartum and Postpartum Bolus Injections of Trace Minerals On Performance of Beef Cows and Calves Grazing Native Range
}

\author{
L.R. Mundell, J.R. Jaeger, J.S. Stevenson, D.M. Grieger, \\ L.A. Pacheco, J.W. Bolte, N.A. Aubel, G.J. Eckerle, M.J. Macek, \\ L.J. Havenga, and KC Olson
}

\section{Introduction}

Adequate dietary intakes of trace minerals are thought necessary to maximize cow reproduction, calf health, and calf performance. Diets grazed by beef cattle are generally deficient to marginal in copper $(\mathrm{Cu})$, manganese $(\mathrm{Mn})$, selenium $(\mathrm{Se})$, and zinc $(\mathrm{Zn})$ concentrations; therefore, these trace minerals are usually added to the diet in supplement form.

The most widely used means of trace-mineral supplementation for grazing cattle is selffed, salt-based, loose mineral supplements. Although cattle do not balance their mineral needs when consuming a self-fed mineral supplement, usually no other practical way of supplying mineral needs exists under grazing conditions. The greatest limitation to using self-fed mineral supplements is variation in animal intake. More direct methods of mineral supplementation include adding minerals to drinking water or feed, oral drenching, ruminal boluses, and injection. Variation in mineral intake is reduced relative to self-fed supplementation, and the additional labor requirement and expense are relatively small.

Delivery of supplemental trace minerals using an injectable solution may be a more reliable means of achieving adequate trace-mineral status than using self-fed, salt-based, loose mineral supplements. Bolus injections of trace minerals have been associated with improved average daily gain, feed efficiency, feed intake, or health status of beef calves fed in confinement; however, trace mineral delivery methods of this type have not been fully evaluated with respect to performance of beef cows and suckling calves. The objective of our study was to evaluate the effects of pre- and postpartum bolus injections of a trace mineral solution on beef cow reproductive performance, body weight change, and body condition score change, as well as performance of suckling calves.

\section{Experimental Procedures}

Angus cross cows and heifers ( $\mathrm{n}=460$; initial body weight 1,095 $\pm 196 \mathrm{lb}$ ) managed in 2 locations were used in our study (193 cows and 81 heifers at Manhattan, KS, and 132 cows and 54 heifers at Hays, KS). At the end of December 2009, cows were stratified by body condition score $(1=$ thin, $9=$ very fat $)$, parity, and predicted calving date and assigned randomly to 1 of 2 treatments: (1) subcutaneous injection with a trace mineral solution (TM; Table 1) or (2) subcutaneous injection with autoclaved physiological saline (SA). Injections were administered to cows ( $1 \mathrm{~mL} / 200 \mathrm{lb}$ body weight) 105 days before the first projected calving date and again approximately 30 days before 
fixed-time artificial insemination. Calves received the same treatment as their dams and were injected ( $1 \mathrm{~mL} / 100 \mathrm{lb}$ body weight $)$ at birth and again at $71 \pm 21$ days of age.

Within location, cows and heifers were managed as a single group from December 17 through the end of the calving season. In Manhattan, cows were evenly distributed by treatment and parity into 5 native pastures on May 15; in Hays, cows were evenly distributed by treatment and parity into 2 native pastures on May 1 . Cows grazed assigned pastures until October 5; self-fed TM supplements (19\% Ca, 6.5\% P, 17\% NaCl, $1300 \mathrm{ppm} \mathrm{Cu}, 26 \mathrm{ppm} \mathrm{Se}$, and 2,000 ppm Zn) and white salt were available to all cattle free choice for a minimum of 12 months before and throughout the study. Availability of self-fed TM and white salt were visually verified on a daily basis.

Cow body weight and body condition measurements were obtained 105 days before the first projected calving date, at calving, at the time of fixed-time artificial insemination, and at weaning. Calf body weight measurements were recorded at birth, on June 16, and at weaning.

Blood samples were collected from each cow 17 and 8 days before fixed-time artificial insemination via jugular venipuncture and immediately placed on ice. Resulting serum was analyzed for progesterone concentration. When either or both samples contained concentrations of progesterone $\geq 1 \mathrm{ng} / \mathrm{mL}$, cows were considered to be cycling.

Ovulation was synchronized using a 5-day Co-Synch + controlled internal drug release (CIDR) protocol, and cows were inseminated 60 to 64 hours after CIDR removal. Cows were exposed to fertile bulls for natural-service breeding beginning 10 days after fixed-time artificial insemination for 50 days. Conception to fixed-time artificial insemination was determined via ultrasound 36 days after artificial insemination and final pregnancy rate was determined via rectal palpation 120 days after artificial insemination.

\section{Results and Discussion}

Change in cow body weight and body condition score from initiation of the study to calving and from artificial insemination breeding to weaning did not differ $(P \geq 0.15)$ between cows injected with TM and cows injected with saline (Tables 1 and 2). Conversely, TM cows had greater $(P=0.04)$ body condition score increase than SA cows between calving and artificial insemination.

The proportion of cows with estrus cycles 17 or 8 days prior to timed artificial insemination was similar $(P \geq 0.51)$ between treatments. In contrast, conception to fixed-time artificial insemination was greater $(P=0.05)$ for cows receiving TM $(60.2 \%)$ than for cows receiving SA (51.2\%); however, overall pregnancy did not differ $(P=0.24)$ between treatments and averaged $92 \%$ (Table 3 ). The strong timed-artificial insemination response to trace mineral injection was not anticipated because all cows in our study had free-choice access to self-fed oral trace mineral supplements and white salt for a minimum of 12 months prior to and during our study. Consumption of self-fed trace mineral on a per-pasture basis was within manufacturer recommendations before and during our study; therefore, we speculated that the trace mineral status of individual 
cows may not have been optimal due to non-consumption or erratic intake of self-fed trace mineral supplement.

Calf body weight at birth did not differ $(P>0.91)$ between treatments (Table 4). Calf average daily gain from birth to June 16 , from June 16 to weaning, and from birth to weaning also did not differ $(P \geq 0.36)$ between TM and SA. Similarly, adjusted 205-day body weights did not differ $(P=0.48)$ between treatments.

\section{Implications}

Under the conditions of our study, pre- and postpartum trace mineral injections improved conception to fixed-time artificial insemination by beef cows. Supplementing trace minerals to beef cows using an injectable solution may be a more reliable way of assuring adequate trace-mineral status than offering a self-fed, salt-based, granular mineral supplement alone; however, further research is warranted to substantiate this idea. At the time of this writing, cost of the injectable trace mineral product used in our study was approximately $\$ 0.40 / \mathrm{mL}$. Cost per dose $(1 \mathrm{~mL} / 200 \mathrm{lb}$ body weight $)$ for a beef cow weighing $1,200 \mathrm{lb}$ was $\$ 2.40$ and total treatment cost (i.e., 2 doses) for a beef cow weighing $1,200 \mathrm{lb}$, as described in our study, was $\$ 4.80$.

Table 1. Effects of pre- and postpartum bolus injections of either a trace-mineral solution or physiological saline $(1 \mathrm{~mL} / 200 \mathrm{lb}$ body weight) on body weight and body weight change of beef cows grazing native range

\begin{tabular}{|c|c|c|c|c|}
\hline \multirow[b]{2}{*}{ Item } & \multicolumn{2}{|c|}{ Treatment } & \multirow[b]{2}{*}{ SE } & \multirow[b]{2}{*}{$P$-value } \\
\hline & Saline & $\begin{array}{c}\text { Trace } \\
\text { mineral }^{a}\end{array}$ & & \\
\hline \multicolumn{5}{|l|}{ Cow body weight, $\mathrm{lb}^{\mathrm{b}}$} \\
\hline Pregnancy check & 1,108 & 1,108 & 5.8 & 0.97 \\
\hline Parturition & 1,090 & 1,089 & 5.6 & 0.96 \\
\hline $\begin{array}{l}\text { Artificial insemination (AI) } \\
\text { breeding }\end{array}$ & 1,175 & 1,175 & 8.0 & 0.98 \\
\hline Weaning & 1,188 & 1,193 & 12.4 & 0.83 \\
\hline \multicolumn{5}{|l|}{ Cow body weight change, $\mathrm{lb}$} \\
\hline Pregnancy check to parturition & -17.4 & -19.2 & 0.09 & 0.85 \\
\hline Parturition to AI breeding & 84.7 & 86.4 & 3.33 & 0.81 \\
\hline AI breeding to weaning & 95.9 & 101.2 & 6.00 & 0.59 \\
\hline
\end{tabular}


Table 2. Effects of pre- and postpartum bolus injections of either a trace-mineral solution or physiological saline ( $1 \mathrm{~mL} / 200 \mathrm{lb}$ body weight) on body condition score and body condition score change of beef cows grazing native range

\begin{tabular}{|c|c|c|c|c|}
\hline \multirow[b]{2}{*}{ Item } & \multicolumn{2}{|c|}{ Treatment } & \multirow[b]{2}{*}{ SE } & \multirow[b]{2}{*}{$P$-value } \\
\hline & Saline & $\begin{array}{c}\text { Trace } \\
\text { mineral }^{a}\end{array}$ & & \\
\hline \multicolumn{5}{|l|}{ Cow BCS ${ }^{b c}$} \\
\hline Pregnancy check & 5.51 & 5.45 & 0.009 & 0.29 \\
\hline Parturition & 5.17 & 5.08 & 0.004 & 0.13 \\
\hline Artificial insemination (AI) & 5.44 & 5.47 & 0.029 & 0.66 \\
\hline Weaning & 5.29 & 5.28 & 0.003 & 0.94 \\
\hline \multicolumn{5}{|l|}{ Cow BCS change } \\
\hline Pregnancy check to parturition & -0.34 & -0.37 & 0.013 & 0.57 \\
\hline Parturition to AI & 0.26 & 0.38 & 0.021 & 0.04 \\
\hline AI to weaning & 0.10 & 0.19 & 0.008 & 0.15 \\
\hline
\end{tabular}

${ }^{a}$ Multimin 90, Multimin USA, Ft. Collins, CO.

${ }^{\mathrm{b}}$ Body condition score units, 1 to 9 scale $(1=$ thin, $9=$ very fat $)$.

${ }^{\mathrm{C}}$ Cow BCS were assigned at pregnancy check (December 17), parturition (average date $=$ April 6), AI breeding (June 16), and weaning (October 29).

Table 3. Effects of pre- and postpartum bolus injections of either a trace-mineral solution or physiological saline $(1 \mathrm{~mL} / 200 \mathrm{lb}$ body weight) on reproductive performance of beef cows grazing native range

\begin{tabular}{|c|c|c|c|c|}
\hline \multirow[b]{2}{*}{ Item } & \multicolumn{2}{|c|}{ Treatment } & \multirow[b]{2}{*}{ SE } & \multirow[b]{2}{*}{$P$-value } \\
\hline & Saline & $\begin{array}{c}\text { Trace } \\
\text { mineral }^{a}\end{array}$ & & \\
\hline $\begin{array}{l}\text { Cows cycling before timed } \\
\text { artificial insemination (AI), \% }\end{array}$ & 56.3 & 59.5 & 0.04 & 0.51 \\
\hline Timed-AI pregnancy, $\%^{\mathrm{c}}$ & 51.2 & 60.2 & 0.03 & 0.05 \\
\hline Final pregnancy, $\%{ }^{\mathrm{d}}$ & 89.9 & 93.0 & 0.02 & 0.24 \\
\hline
\end{tabular}

${ }^{a}$ Multimin 90, Multimin USA, Ft. Collins, CO.

${ }^{\mathrm{b}}$ Determined from serum samples collected 17 and 8 days before timed AI.

c Proportion of cows classified as being pregnant from timed AI only.

${ }^{\mathrm{d}}$ Proportion of cows classified as pregnant from either timed AI or natural-service breeding. 
Table 4. Performance of beef calves treated at birth and at $71 \pm 21$ days of age with bolus injections of either a trace mineral solution or physiological saline $(1 \mathrm{~mL} / 100 \mathrm{lb}$ body weight)

\begin{tabular}{|c|c|c|c|c|}
\hline \multirow[b]{2}{*}{ Item } & \multicolumn{2}{|c|}{ Treatment } & \multirow[b]{2}{*}{ SE } & \multirow[b]{2}{*}{$P$-value } \\
\hline & Saline & $\begin{array}{c}\text { Trace } \\
\text { mineral }^{\text {a }}\end{array}$ & & \\
\hline \multicolumn{5}{|l|}{ Calf body weight, $1 b^{b}$} \\
\hline Birth & 84.7 & 84.7 & 0.02 & 0.92 \\
\hline Artificial insemination & 324.6 & 322.4 & 0.57 & 0.90 \\
\hline Weaning & 469.2 & 461.1 & 2.16 & 0.28 \\
\hline Adjusted 205-day body weight ${ }^{c}$ & 510.5 & 505.9 & 1.90 & 0.48 \\
\hline \multicolumn{5}{|l|}{ Average daily gain, lb } \\
\hline Early season (birth to June 16) & 2.07 & 2.07 & 0.009 & 0.89 \\
\hline Late season (June 16 to weaning) & 2.01 & 1.96 & 0.022 & 0.36 \\
\hline Overall (birth to weaning) & 2.07 & 2.05 & 0.011 & 0.48 \\
\hline
\end{tabular}

${ }^{a}$ Multimin 90, Multimin USA, Ft. Collins, CO

${ }^{\mathrm{b}}$ Calf body weights were measured at birth (average date $=$ April 6), artificial insemination breeding of cows (June 16), and weaning (October 29).

c Adjusted 205-day body weight $=$ birth weight $\times 205 \times$ overall average daily gain. 